\title{
Menstrual Blood Loss and Fibrin Degradation Products
}

\author{
SUSAN K. COLE, A. R. CLARKSON
}

British Medical fournal, 1972, 1, 78-79

Haemoglobin was estimated as cyanmethaemoglobin in a Summary

As part of a large-scale study of menstrual blood loss in the community serum fibrin degradation products were measured soon after menstruation in 331 women. No significant correlation was found between the amount of blood lost and the serum level of fibrin degradation products. These findings conflict with reports suggesting that excessive intrauterine fibrinolysis, which may play a part in menorrhagia, is associated with raised serum F.D.P. concentrations.

\section{Introduction}

Excessive intrauterine fibrinolysis may be implicated in some types of menorrhagia. Rybo (1966) found that women with menstrual blood losses of $80 \mathrm{ml}$ or more had increased amounts of tissue plasminogen activators in the endometrium; and some women with menorrhagia have reported a subjective improvement in menstrual loss after treatment with an antifibrinolytic agent (Nilsson and Bjorkman, 1965). Basu (1970) reported that women complaining of menorrhagia had a higher concentration of circulating fibrin degradation products (F.D.P.) than a group of normal controls. In this paper we report the serum F.D.P. levels found during a large-scale study of menstrual blood losses in the community.

\section{Patients and Methods}

Three hundred and forty-eight women aged 17 to 44 years$94 \%$ of the available non-pregnant women in a Northumbrian mining village-were investigated during a community study of menstrual blood loss (Cole et al., 1971). Serum F.D.P. were estimated in 331 of these women. The age distribution is shown in Table $\mathrm{I}$.

TABLE I-Age of 331 Women Studied

\begin{tabular}{ccccc|c|c|c}
\hline Age in years &. & $\ldots$ & $\ldots$ &.. & $17-24$ & $25-34$ & $\begin{array}{c}35-44 \\
134\end{array}$ \\
No. $\quad$. &. &.. &. &.. & 76 & 121 & \\
\hline
\end{tabular}

Mean age $31 \cdot 5$ years.

Menstrual blood loss as quoted here is the mean of the measured loss of two consecutive periods, except for 24 cases in which ony one period was measured. The used sanitary towels or tampons were soaked in a measured volume of iron-free water to remove all blood. The iron in the wash was measured by the method of Cheyne and Shepherd (1970) and the blood equivalent of iron was calculated from the haematological data of each patient. Previous recovery experiments, using sanitary towels treated with measured amounts of blood, gave a mean ratio of "calculated blood" to "known blood" of $101 \%$. Blood specimens were taken in the patient's home, at different times of day, within a few days of the end of a menstrual period. The subjects were not rested, and blood was taken from the cubital vein with the minimum of venous compression.

Princess Mary Maternity Hospital, Newcastle upon Tyne NE2 3BD SUSAN K. COLE, M.D., M.R.C.O.G., Scientific Staff, M.R.C. Reproduction and Growth Unit (Present Address. St. Helier Hospital, Carshalton).

Unicam SP 600 spectrophotometer.

Serum F.D.P. were measured by the tanned red cell haemagglutination inhibition immunoassay (Merskey et al., 1966; Das, 1970). The human group O Rh-negative cells used in the assay were prepared according to the method of Hoq and Das (1971) and provided a mean sensitivity of $0.47 \mu \mathrm{g}$ of fibrinogen equivalent per ml. Each specimen was coded before the assay, which was performed by one of us (A.R.C.) in complete ignorance of the clinical details. The mean serum F.D.P. concentrations of 56 healthy control subjects ( 31 men and 25 women) of similar age distribution and using the same assay materials was $10.52 \pm 6.16 \mu \mathrm{g} / \mathrm{ml}$, a figure somewhat higher than that found by Das et al. (1967), who used sensitized sheep cells.

\section{Results}

The menstrual blood loss ranged from $0 \cdot 1$ to $280 \mathrm{ml}$ per period with a pronounced negative skew on the distribution curve (see Chart). Twenty-three women were using an oral contraceptive (pill) and 22 an intrauterine contraceptive device (coil), both of which affected blood loss (Cole et al., 1971). As oral contraceptives are known to influence clotting mechanisms the groups using contraceptives were considered separately from the remaining 268 women. The latter were divided into groups according to menstrual blood loss (Table II). The mean F.D.P. concentration for the whole population was $12.09 \pm 6.54 \mu \mathrm{g} / \mathrm{ml}$.

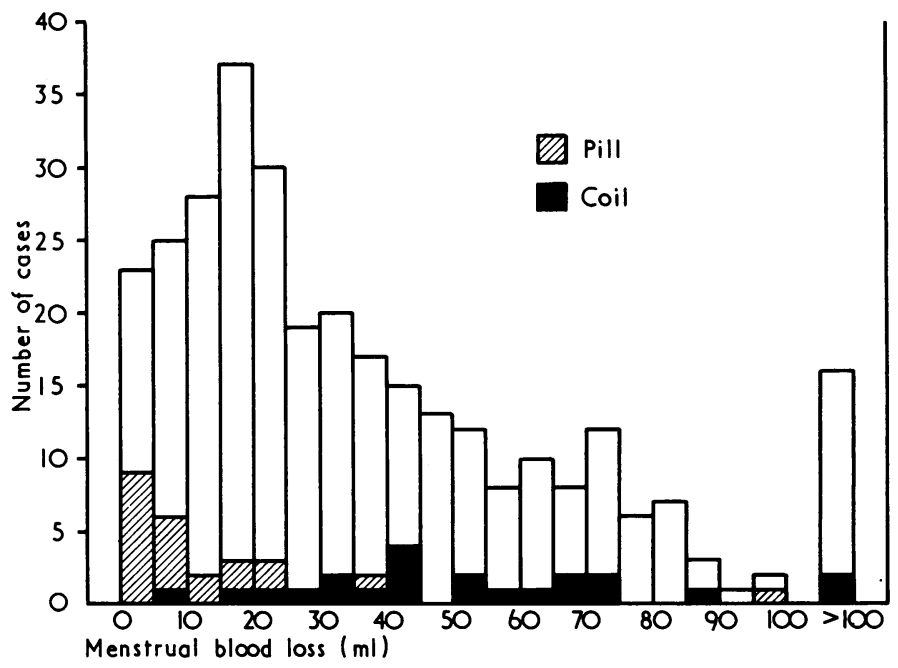

Menstrual blood losses in surveyed population.

TABLE II-F.D.P. and Menstrual Blood Loss

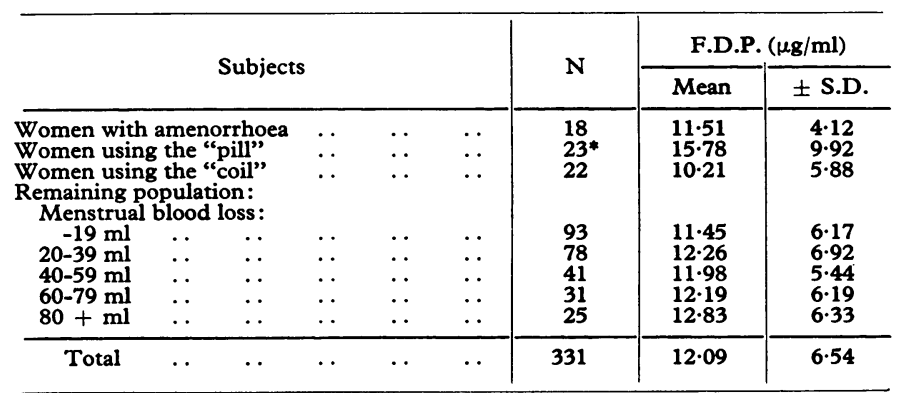

One subject did not menstruate. 
The mean F.D.P. concentration of the women taking oral contraceptives, $15 \cdot 78 \pm 9.92 \mu \mathrm{g} / \mathrm{ml}$, was higher than that of any other group, but this figure was influenced by two values of 37.6 and $45.1 \mu \mathrm{g} / \mathrm{ml}$, which were much higher than in any other women in the survey. There is no statistically significant difference between any of the groups shown in Table II; and the correlation coefficient $(r=0.02)$ between menstrual blood loss and serum F.D.P. is also not significant.

\section{Discussion}

Using the tanned red cell haemagglutination inhibition immunoassay, Basu (1970) showed a significant rise in serum F.D.P. in all stages of the menstrual cycle in women complaining of menorrhagia, compared with a control group. Moreover, in both normal and abnormal groups there was a peak in serum F.D.P. concentration coinciding with menstruation. Basu (1970) concluded that these systemic manifestations of increased invivo fibrinolysis were evidence of intensive local intrauterine activity. However, Das et al. (1967) were unable to find any cyclical fluctuation in systemic F.D.P. concentration in four normal women and, in particular, there was no peak during menstruation. Moreover, though many of the women in the present study had menstrual losses as large as those experienced by women who complain of menorrhagia (Hytten et al., 1964) we were unable to show a positive correlation between menstrual loss and circulating F.D.P. concentration.

Why our findings differ from Basu's (1970) is difficult to explain. His patients may have differed in some relevant way from our subjects, since women who seek medical help may do so primarily because of a recent change in the volume of blood lost at menstruation, and such a change might be associated with temporarily increased local intrauterine fibrinolysis and so be reflected in raised systemic levels of serum F.D.P. However, this explanation is unlikely as Rybo (1966) showed that increased intrauterine fibrinolysis, as measured by high levels of endometrial plasminogen activator, is associated with the actual volume of menstrual blood lost rather than with the complaint of menorrhagia.

Minor, but important, differences in the F.D.P. assay technique between Basu's (1970) laboratory and our own may also be relevant; in particular, the specificity of the antisera used, with special reference to the relative sensitivity of tests to detect the antigenically dissimilar D and E fragments. Checking our own antiserum with purified $D$ and $E$ products has shown extreme sensitivity to fragment $D$ and only slightly less sensitivity to $E$.

Consideration of previous studies in which serum F.D.P. estimations have often failed to show evidence of intense localized fibrin deposition and fibrinolysis, as in the case of renal homotransplantation (Colman et al., 1969; Clarkson et al., 1970) and of proliferative glomerulonephritis (Clarkson et al., 1971), makes the absence of a significant rise in serum F.D.P. in women with heavy menstrual blood loss, as reported in this paper, not unexpected. Thus, from a practical point of view, at the present time we have no reason to believe that isolated or serial measurements of serum F.D.P. in women complaining of menorrhagia will assist the gynaecologist in selecting those patients who might benefit from oral antifibrinolytic agents (Nilsson and Rybo, 1971).

We wish to thank Dr. A. J. G. Newton and his partners and the patients in Broomhill, Northumberland, for their co-operation. We are also grateful for criticism and advice during the preparation of this paper from Dr. J. D. Cash, Deputy Director, S.E. Scotland Regional Blood Transfusion Centre. Mr. J. Barclay helped with the F.D.P. assays.

\section{References}

Basu, H. K. (1970). British Medical fournal, $1,74$.

Cheyne, G. A., and Shepherd, M. M. (1970). fournal of Medical Laboratory Technology, 27, 350.

Clarkson, A. R., Morton, J. B., and Cash, J. D. (1970). Lancet, 2, 1220.

Clarkson, A. R., MacDonald, M. K., Petrie, J. J. B., Cash, J. D., and Robson, J. S. (1971). British Medical fournal, 3, 447.

Cole, S. K., Billewicz, W. Z., and Thomson, A. M. (1971). Fournal of Obstetrics and Gynaecology of the British Commonwealth, 78, 933.

Colman, R. W. Braun, W. E., Busch, G. J., Dammin, G. J., and Merrill, J. P. (1969). New England fournal of Medicine, 281, 685.

Das, $\dot{P}$. C. (1970). Fournal of Clinical Pathology, 23, 149.

Das, P. C., Allan, A. G. E., Woodfield, D. G., and Cash, J. D. (1967). British Medical Fournal, 4, 718.

Hoq, M., and Das, P. C. (1971). Scandinavian fournal of Haematology, Suppl. No. 13, p. 101.

Hytten, F. E., Cheyne, G. A., and Klopper, A. I. (1964). Fournal of Obstetrics and Gynaecology of the British Commonwealth, 71, 255.

Merskey, C., Kleiner, G. J., and Johnson, A. J. (1966). Blood, 28, 1.

Nilsson, I. M., and Bjorkman, S. E. (1965). Acta Medica Scandinavica,

177,445 .
Nilsson, L., and Rybo, G. (1971). American fournal of Obstetrics and Gynecology, 110, 713 .

Rybo, G. (1966). Acta Obstetricia et Gynecologica Scandinavica, 45, 429.

\title{
Bread Iodine Content and Thyroid Radioiodine Uptake: a Tale of Two Cities
}

\author{
BERNARD A. SACHS, EDWARD SIEGEL， BENJAMIN N. HORWITT, ELSIE SIEGEL
}

British Medical fournal, 1972, 1, 79-81

\section{Summary}

The iodine content of bread consumed in the Bronx, New York, was found to be significantly lower than that of bread consumed in Columbia, Missouri. This difference in dietary

Albert Einstein College of Medicine, Bronx, New York

BERNARD A. SACHS, M.D., Associate Clinical Professor of Medicine; and Senior Endocrinologist, Montefiore Hospital and Medical Center, Bronx, New York

University of Missouri School of Medicine, Columbia, Missouri EDWARD SIEGEL, PH.D., Professor of Radiological Sciences and

Medicine
ELSIE SIEGEL, M.s., Research Associate, Department of Radiology

Bio-Science Laboratories, Van Nuys, California

BENJAMIN N. HORWITT, PH.D., Director, Department of Endocrinology intake of iodine could account for the lowered range of normal values for 24-hour ${ }^{131}$ I uptake tests in Columbia, and the persistence of the same normal range for this test over the past 28 years in the Bronx. A population with high iodine intake requires higher doses of radioactive iodine in the diagnosis and treatment of thyroid disease. Questions are raised regarding the relationship of high iodine intake to the risk of developing thyrotoxicosis.

\section{Introduction}

The 24-hour thyroidal uptake of radioiodine is accepted as a reliable index of thyroid function. Well-known factors that influence the uptake are iodine-containing medications or diagnostic procedures using iodine-containing contrast media. In the absence of these the uptake of radioiodine by the 